Jurnal Evaluasi dan Pembelajaran

Volume 3 Nomor 1, Tahun 2021

Available online at https://jepjurnal.stkipalitb.ac.id/index.php/hepi

\title{
PENINGKATAN AKTIVITAS DAN PRESTASI BELAJAR AL-QUR'AN MENGGUNAKAN ALAT PERAGA REALIA
}

\author{
Ratnika Wati \\ SDN 4 Sawah Lama
}

\begin{abstract}
Abstrak
Penelitian ini bertujuan untuk meningkatkan aktivitas dan prestasi belajar siswa dalam pembelajaran Pendidikan Agama Islam (Pendais) Alqur'an pada siswa Kelas V SDN 4 Sawah Lama Bandar Lampung TP 2019/2020. Penelitian ini menerapkan Penelitian Tindakan Kelas dilakukan tindakan dalam tiga siklus pembelajaran, masing-masing terdiri dari perencanaan, tindakan, observasi, refleksi. Waktu penelitian semester Pertama Tahun Pelajaran 2019/2020, Subjek terdiri dari 30 Siswa Kelas V. Data penelitian diambil dari observasi aktivitas, tes akhir siklus, dan observasi guru teman sejawat. Analisis data menggunakan prosentase sederhana. Hasil penelitian aktivitas belajar siklus I rata-rata $68,5 \%$, Siklus II rata-rata $87,5 \%$, siklus III rata-rata 99,5\%. Prestasi hasil belajar (ketuntasan): Siklus I tuntas $64 \%$, Siklus II tuntas $84 \%$, Siklus III tuntas $97 \%$. Berdasarkan hasil penelitian dan pembahasan, dapat disimpulkan penggunaan alat peraga realia dapat meningkatkan aktivitas dan prestasi belajar Pendidikan Agama Islam (Pendais) Al-Qur'an pada Siswa Kelas V SDN 4 Sawah Lama Bandar Lampung TP 2019/2020.
\end{abstract}

Kata Kunci: Aktivitas, Alat Peraga Realia, Prestasi Belajar

\begin{abstract}
This study aims to increase student activity and learning achievement in learning Islamic Religious Education (Pendais) Alquran in Class V students of SDN 4 Sawah Lama Bandar Lampung TP 2019/2020. This research applies Classroom Action Research to take action in three learning cycles, each of which consists of planning, acting, observing, reflecting. Research time for the first semester of the 2019/2020 academic year, the subjects consisted of 30 Class V students. Research data were taken from activity observations, final cycle tests, and peer teacher observations. Data analysis used simple percentages. The results of the study of learning activities in cycle I an average of $68.5 \%$, cycle II an average of $87.5 \%$, cycle III an average of $99.5 \%$. Achievement of learning outcomes (completeness): Complete cycle I $64 \%$, Cycle II completed $84 \%$, Cycle III completed $97 \%$. Based on the results of research and discussion, it can be concluded that the use of realia teaching aids can increase the activity and learning achievement of Islamic Religious Education (Pendais) Al-Qur'an in Class V Students of SDN 4 Sawah Lama Bandar Lampung TP 2019/2020.
\end{abstract}

Keywords: Activities, Realia Teaching Aids, Learning Achievement

\section{Pendahuluan}

Pembelajaran merupakan salah satu tindakan edukatif yang dilakukan oleh guru di kelas. Tindakan kelas dikatakan bersifat edukatif bila berorientasi pada pengembangan diri 
atau pribadi siswa secara utuh, artinya pengembangan pengetahuan, keterampilan dan sikap. Oleh karena itu guru harus kompeten dalam menciptakan aktivitas pembelajaran yang sesuai dengan ketiga aspek tersebut. Selain itu faktor yang ikut berperan dalam pembelajaran adalah kesiapan mental pembelajaran sebelumnya yang bersifat sederhana. Selama ini ada anggapan bahwa belajar Pendais itu sulit, karena tidak tuntasnya dalam belajar Pendais pada tahap sebelumnya, dan dengan demikian sebaliknya untuk senang belajar karena merasa paham pada konsep yang mereka pelajari sebelumnya. Oleh karena itu setiap konsep perlu difahami dengan baik oleh peserta didik.

Keberhasilan suatu pembelajaran tergantung bagaimana interaksi antara guru dengan siswa. Interaksi guru dengan siswa dapat berjalan dengan baik apabila guru dalam mengelola kelas menggunakan strategi pembelajaran yang relevan. Dalam mengelola kelas langkah awal yang perlu diketahui oleh guru adalah, dengan siapa atau siswa yang bagaimana yang akan dihadapi. Tanpa paham tentang kondisi peserta didik mustahil guru dapat memilih strategi pembelajaran yang tepat dan materi pembelajaran yang sesuai. Untuk pembelajaran Pendidikan Agama Islam (Pendais) yang menjadi fokus dalam pembelajaran adalah adanya interaksi antara siswa dengan objek atau alam secara langsung, sehingga siswa dapat menemukan konsep dan membangun dalam struktur kognitifnya.

Dalam pembelajaran Pendais materi yang satu sering mendasai materi yang lain, sehingga guru sangat perlu memperhatikan materi prasyarat untuk mempelajari topik tertentu. Selain itu tahap berfikir siswa SD masih dalam tahap berfikir konkrit, sehingga dalam menyampaikan materi guru perlu memperhatikan latar belakang siswa yang akan diajarkannya dan sarana atau peraga yang akan dipakai sebagai alat bantu mengajar agar siswa lebih cepat menyerap materi yang diberikan. Alat Peraga yang dipakai guru dapat berupa benda-benda nyata yang ada di sekitarnya, atau benda konkrit yang dapat lebih meningkatkan aktivitas dan prestasi belajar Pendidikan Agama Islam (Pendais) siswa Kelas V SDN 4 Sawah Lama Bandar Lampung TP 2019/2020. berikut:

Hasil pengamatan pra penelitian prestasi belajar Pendais Kelas V diperoleh sebagai

Tabel 1. Nilai Pendais Kelas V Pra Penelitian TP 2019/2020

\begin{tabular}{lcccl}
\hline No & Nilai & Frekwensi & Persentase & Keterangan \\
\hline 1 & $80-100$ & - & - & Sangat Baik \\
\hline 2 & $60-79$ & 5 & 17 & Baik \\
\hline 3 & $40-59$ & 9 & 30 & Cukup \\
\hline 4 & $20-39$ & 16 & 53 & Kurang \\
\hline & Total & 30 & 100 & \\
\hline
\end{tabular}

Berdasarkan tabel 1 di atas, keadaan siswa untuk nilai mata pelajaran Pendais rendah, siswa yang memperoleh nilai sangat Baik 0\%, Baik 17\%, nilai Cukup 30\% dan kurang 53\%. Memperhatikan kenyataan di atas peneliti berupaya untuk meningkatkan aktivitas belajar dan prestasi belajar siswa pada mata pelajaran Pendidikan Agama Islam (Pendais) di Kelas V SDN 4 Sawah Lama Bandar Lampung. Untuk pemecahan masalah ini diperlukan tindakan-tindakan dengan memanfaatkan alat peraga realia. Melalui pemanfaatan alat peraga realia dalam pembelajaran diharapkan pembelajaran lebih bermakna sehingga aktivitas dan prestasi belajarnya dapat meningkat.

Menurut Sadiman (Sidiq dkk, 2008:2-16) kata Alat Peraga berasal dari bahasa latin dan bentuk jamak dari kata medium yang artinya perantara atau pengantar. Alat Peraga adalah perantara atau pengantar pesan dari pengirim ke penerima pesan. Menurut Gagne Alat Peraga adalah berbagai jenis komponen dalam lingkungan siswa yang dapat merangsangnya (Sidiq dkk, 2008: 1-16). 
Oemar (Hidayat dkk, 2008:7-14) menyatakan bahwa Alat Peraga pendidikan adalah alat, metode, dan teknik yang digunakan dalam rangka lebih mengefektifkan komunikasi dan interaksi antara guru dan siswa dalam proses pendidikan dan pengajaran di sekolah. Sedangkan Alat Peraga pengajaran Kosasih Djahiri (Hidayat dkk, 2008:7-14) adalah alat bantu yang dapat memperlancar keberhasilan mengajar. Alat bantu mengajar ini berfungsi membantu efesiensi pencapaian tujuan. Oleh karena itu dalam proses belajar mengajar guru harus selalu menghubungkan alat bantu mengajar dengan kegiatan mengajarnya.

Alat peraga realia adalah alat peraga yang berupa benda-benda aslinya seperti apa adanya atau aslinya tanpa ada perubahan. Penggunaan alat peraga realia dalam pembalajaran sangat baik dilakukan karena dapat menampilkan ukuran, suara, dan gerakan sesungguhnya.

Menurut Rowntree (Hanfiah dan Suhana, 2009) menyatakan: Realia merupakan perangsang nyata, seperti orang, binatang, benda, peristiwa yang diamati peserta didik. Dalam realia orang hanya menjadi objek pengamatan atau studi. Menurut Prasetiyo (Hanafiah dan Suhana, 2009) Realia adalah benda-benda nyata seperti apa adanya atau aslinya tanpa perubahan. Pemanfaatan realia dalam proses pembelajaran akan membantu siswa lebih aktif dalam mengamati, menangani, memanipulasi, mendiskusikan, dan akhirnya dapat menjadi alat untuk meningkatkan kemauan siswa untuk menggunakan sumber-sumber belajar serupa. Dalam mata pelajaran Pendais, misalnya kegiatan keagamaan diharapkan dapat menyebabkan timbulnya minat siswa terhadap pengetahuan membaca , menulis atau melakukan ibadah. Contoh lain pemanfaatan realia, misalnya guru menunjukkan Video melaksanakan kegiatan ibadah.

Pembelajaran menggunakan alat peraga realia, merupakan pembelajaran yang memaksimalkan penggunaan alat peraga konkrit yang ada di lingkungan siswa, sehingga memungkinkan siswa untuk belajar menemukan dan mengelola informasi dan memecahkan masalah yang mereka peroleh dari lingkungan mereka. Untuk mencapai tujuan tersebut siswa harus belajar mencari informasi maupun masalah yang yang ada di lingkungan mereka sehingga siswa akan lebih aktif karena harus mencari dan memecahkan masalah yang ditemukan. Pembelajaran menggunakan alat peraga realia diprediksi mampu meningkatkan aktivitas belajar. Jika aktivitas belajar siswa telah meningkat, diharapkan dapat meningkatkan kerjasama positif antar siswa dan dapat meningkatkan prestasi belajar siswa.

Mengingat pendidikan di sekolah dasar merupakan awal kegiatan belajar yang berdurasi panjang atau paling lama, maka pencapaian hasil belajar dapat optimal. Guru adalam pembelajaran perlu memperhatikan tentang karakteristik anak usia sekolah dasar.

\section{Metode}

Penelitian ini menerapkan Penelitian Tindakan Kelas dilakukan tindakan dalam tiga siklus pembelajaran, masing-masing terdiri dari perencanaan, tindakan, observasi, refleksi. subjek penelitian yaitu siswa Kelas V SDN 4 Sawah Lama Bandar Lampung Tahun Pelajaran 2019/2020 dengan jumlah 30 Siswa. Indikator keberhasilan pada penelitian ini adalah (1) apabila adanya peningkatan pada setiap siklus dalam hal aktivitas siswa selama proses pembelajaran Pendais Al-Qur'an menggunakan alat peraga realia. (2) Apabila adanya peningkatan pada setiap siklus dalam hal prestasi belajar siswa setelah melaksanakan proses pembelajaran Pendais Al-Qur'an menggunakan alat peraga realia.

\section{Hasil dan Pembahasan}

Hasil penelitian terdiri dari tiga siklus. Siklus pertama diperoleh hasil aktivitas siswa terlihat pada tabel 2 sebagai berikut: 
Jurnal Evaluasi dan Pembelajaran, 3 (1), Maret 2021 - 16

Ratnika Wati

Tabel 2. Data Aktivitas Siswa Pada Pembelajaran Pendais Siklus I

\begin{tabular}{cccc}
\hline \multirow{2}{*}{ Kegiatan } & \multicolumn{2}{c}{ Jumlah Siswa yang Beraktivitas } & \multirow{2}{*}{ Ket Aktif (\%) } \\
\cline { 2 - 3 } & Ya & Tidak & \\
\hline Pembelajaran 1 & & 10 & 67 \\
\hline A & 20 & 7 & 77 \\
\hline B & 23 & 12 & 60 \\
\hline C & 18 & 68 \\
\hline \multicolumn{4}{c}{ Rata-rata Pembelajaran 1 } \\
\hline Pembelajaran 2 & 22 & 11 & 73 \\
\hline A & 19 & 9 & 63 \\
\hline C & 21 & 70 \\
\hline \multicolumn{2}{c}{ Rata-rata Pembelajaran 2 } \\
\hline
\end{tabular}

Berdasarkan tabel 2 di atas diperoleh gambaran umum bahwa aktivitas siswa pada Siklus I dalam pembelajaran I menggunakan alat peraga realia siswa aktif memperhatikan saat pembelajaran jumlah 20 siswa (67\%), Aktif mengerjakan tugas 23 Siswa (77\%), Siswa merasa senang mengikuti pembelajaran 18 siswa $(60 \%)$, rata-rata $68 \%$ kriteria aktif. Sedangkan aktivitas siswa pada pembelajaran 2 menggunakan alat peraga realia siswa aktif memperhatikan saat pembelajaran jumlah 22 siswa (73\%), Aktif mengerjakan tugas 19 Siswa $(63 \%)$, Siswa merasa senang mengikuti pembelajaran 21 siswa $(70 \%)$, rata-rata $69 \%$ kriteria aktif. Perolehan nilai tes siswa dijelaskan pada tabel 3 sebagai berikut;

Tabel 3. Data Ketuntasan Siswa Siklus I

\begin{tabular}{ccccccc}
\hline No & & Nilai & Frekwensi & Persentase & \multicolumn{2}{c}{ Kria Ketuntasan } \\
\cline { 4 - 6 } & & & & Tuntas & Belum Tuntas \\
\hline 1 & $80-100$ & 2 & 7 & T & - \\
\hline 2 & $60-79$ & 17 & 57 & T & - \\
\hline 3 & $40-59$ & 11 & 36 & & BT \\
\hline 4 & $20-39$ & - & - & - & - \\
\hline
\end{tabular}

Berdasarkan tabel 3. di atas yang mencapai ketuntasan berjumlah 19 Siswa (64\%), sedangkan yang belum tuntas berjumlah 11 Siswa (36\%). Selanjutnya aktivitas siswa pada siklus II di jelaskan pada tabel 4 . berikut ini:

Tabel 4. Data Aktivitas Siswa Pada Pembelajaran Pendais Siklus II

\begin{tabular}{cccc}
\hline \multirow{2}{*}{ Kegiatan } & \multicolumn{2}{c}{ Jumlah Siswa yang Beraktivitas } & \multirow{2}{*}{ Ket Aktif (\%) } \\
\cline { 2 - 3 } & Ya & Tidak & \\
\hline Pembelajaran 1 & & 6 & 80 \\
\hline A & 24 & 3 & 90 \\
\hline B & 27 & 2 & 93 \\
\hline C & 28 & 87 \\
\hline \multicolumn{2}{c}{ Rata-rata Pembelajaran 1 } & 83 \\
\hline Pembelajaran 2 & 5 & 90 \\
\hline A & 25 & 3 & 90 \\
\hline B & 27 & 88 \\
\hline C & 27 & \\
\hline
\end{tabular}

Berdasarkan tabel 4. di atas diperoleh gambaran umum bahwa aktivitas siswa pada Siklus II dalam pembelajaran 1 menggunakan alat peraga realia siswa aktif memperhatikan saat pembelajaran jumlah 24 siswa (80\%), Aktif mengerjakan tugas 27 Siswa (90\%), Siswa 
merasa senang mengikuti pembelajaran 28 siswa (93\%), rata-rata $87 \%$ kriteria aktif. Sedangkan aktivitas siswa pada pembelajaran 2 menggunakan alat peraga realia siswa aktif memperhatikan saat pembelajaran jumlah 25 siswa (83\%), Aktif mengerjakan tugas 27 Siswa $(90 \%)$, Siswa merasa senang mengikuti pembelajaran 27 siswa $(90 \%)$, rata-rata $88 \%$ kriteria aktif. Perolehan nilai tes siswa siklus II dijelaskan pada tabel 5. sebagai berikut;

Tabel 5. Data Ketuntasan Siswa Siklus II

\begin{tabular}{cccccc}
\hline No & Nilai & Frekwensi & Persentase & \multicolumn{2}{c}{ Kria Ketuntasan } \\
\cline { 5 - 6 } & & & & Tuntas & Belum Tuntas \\
\hline 1 & $80-100$ & 5 & 17 & T & - \\
\hline 2 & $60-79$ & 20 & 67 & T & - \\
\hline 3 & $40-59$ & 5 & 16 & & BT \\
\hline 4 & $20-39$ & - & - & - & - \\
\hline
\end{tabular}

Berdasarkan tabel 5. di atas prestasi hasil belajar siswa yang mencapai ketuntasan berjumlah 25 Siswa (84\%), sedangkan yang belum tuntas berjumlah 5 Siswa (16\%). Selanjutnya aktivitas siswa di jelaskan pada tabel 6 berikut ini;

Tabel 6. Data Aktivitas Siswa Pada Pembelajaran Pendais Siklus III

\begin{tabular}{|c|c|c|c|}
\hline \multirow[t]{2}{*}{ Kegiatan } & \multicolumn{2}{|c|}{ Jumlah Siswa yang Beraktivitas } & \multirow[t]{2}{*}{ Ket Aktif (\%) } \\
\hline & Ya & Tidak & \\
\hline \multicolumn{4}{|c|}{ Pembelajaran 1} \\
\hline $\mathrm{A}$ & 30 & - & 100 \\
\hline B & 29 & 1 & 97 \\
\hline $\mathrm{C}$ & 30 & - & 100 \\
\hline \multicolumn{3}{|c|}{ Rata-rata Pembelajaran 1} & 99 \\
\hline \multicolumn{4}{|c|}{ Pembelajaran 2} \\
\hline $\mathrm{A}$ & 30 & - & 100 \\
\hline B & 30 & - & 100 \\
\hline $\mathrm{C}$ & 30 & - & 100 \\
\hline \multicolumn{3}{|c|}{ Rata-rata Pembelajaran 2} & 100 \\
\hline
\end{tabular}

Berdasarkan tabel 6 di atas diperoleh gambaran umum bahwa aktivitas siswa pada Siklus III dalam pembelajaran 1 menggunakan alat peraga realia siswa aktif memperhatikan saat pembelajaran jumlah 30 siswa (100\%), Aktif mengerjakan tugas 29 Siswa (97\%), Siswa merasa senang mengikuti pembelajaran 30 siswa (100\%), rata-rata 99\% kriteria aktif. Sedangkan aktivitas siswa pada pembelajaran 2 menggunakan alat peraga realia siswa aktif memperhatikan saat pembelajaran jumlah 30 siswa (100\%), Aktif mengerjakan tugas 30 Siswa (100\%), Siswa merasa senang mengikuti pembelajaran 30 siswa (100\%), rata-rata 100\% kriteria aktif. Perolehan nilai tes siswa dijelaskan pada tabel 7. sebagai berikut;

Tabel 7. Data Ketuntasan Siswa Siklus III

\begin{tabular}{|c|c|c|c|c|c|}
\hline \multirow[t]{2}{*}{ No } & \multirow[t]{2}{*}{ Nilai } & \multirow[t]{2}{*}{ Frekwensi } & \multirow[t]{2}{*}{ Persentase } & \multicolumn{2}{|c|}{ Ketuntasan } \\
\hline & & & & Tuntas & Belum Tuntas \\
\hline 1 & $80-100$ & 11 & 37 & $\mathrm{~T}$ & - \\
\hline 2 & $60-79$ & 18 & 60 & $\mathrm{~T}$ & - \\
\hline 3 & $40-59$ & 1 & 3 & - & BT \\
\hline 4 & $20-39$ & - & - & - & - \\
\hline
\end{tabular}


Berdasarkan tabel 7 nilai prestasi hasil belajar siswa yang mencapai ketuntasan berjumlah 29 Siswa (97\%), sedangkan yang belum tuntas berjumlah 1 Siswa (3\%).

Berdasarkan data-data yang diperoleh selama pelaksanaan pembelajaran Pendais menggunakan alat peraga realia pada siswa SDN 4 Sawah Lama TP 2019/2020, yang dilaksanakan dalam tiga siklus penelitian adalah sebagai berikut: aktivitas siswa dari siklus ke siklus mengalami peningkatan yang baik yaitu: Siklus I jumlah siswa yang memperhatikan saat pembelajaran berlangsung pertemuan 1 dan 2 rata-rata $70 \%$, siswa yang aktif melaksanakan tugas pertemuan 1 dan 2 rata-rata $70 \%$, siswa yang merasa senang mengikuti pelajaran pertemuan 1 dan 2 rata-rata 65 Pada siklus II jumlah siswa yang memperhatikan saat pembelajaran berlangsung pertemuan 1 dan 2 rata-rata 81,5\%, siswa yang aktif melaksanakan tugas pertemuan 1 dan 2 rata-rata $90 \%$, siswa yang merasa senang mengikuti pelajaran pertemuan 1 dan 2 rata-rata 91,5\%. Pada Siklus III jumlah siswa yang memperhatikan saat pembelajaran berlangsung pertemuan 1 dan 2 rata-rata 100\%, siswa yang aktif melaksanakan tugas pertemuan 1 dan 2 rata-rata 98,5\%, siswa yang merasa senang mengikuti pelajaran pertemuan 1 dan 2 rata-rata 100\%. Berdasarkan hasil dari penelitian pembelajaran dari siklus I sampai dengan siklus III, dapat disimpulkan bahwa aktivitas belajar siswa meningkat.

Setelah melaksanakan proses pembelajaran Pendais menggunakan alat peraga realia prestasi hasil belajar siswa menunjukkan Siklus I adalah 64\%, Siklus II adalah $84 \%$, Siklus III adalah $97 \%$. Berdasarkan data tersebut diatas dapat disimpulkan bahwa prestasi belajar siswa meningkat. Secara keseluruhan aktivitas belajar siklus I rata-rata 68,5\%, Siklus II ratarata $87,5 \%$, siklus III rata-rata 99,5\% (siklus I ke siklus II meningkat 19\%, siklus II ke siklus III meningkat $12 \%$, aktivitas siswa meningkat rata-rata $15,5 \%$.

Prestasi hasil belajar (ketuntasan) Siklus I rata-rata 19 (tuntas 64\%), Siklus II rata-rata 25 (tuntas 84\%), Siklus III rata-rata 29 (tuntas 97\%). Artinya dari siklus I ke Siklus II meningkat $20 \%$, Siklus II ke siklus III meningkat $13 \%$, atau hasil belajar siswa meningkat rata-rata $16,5 \%$

\section{Simpulan}

Berdasarkan hasil penelitian dan pembahasan, dapat disimpulkan sebagai berikut:

1. Penggunaan alat peraga realia dapat meningkatkan aktivitas belajar Pendidikan Agama Islam (Pendais) Al-Qur'an pada siswa Kelas V SDN 4 Sawah Lama Bandar Lampung TP 2019/2020.

2. Penggunaan alat peraga realia dapat meningkatkan prestasi belajar Pendidikan Agama Islam (Pendais) Al-Qur'an pada siswa Kelas V SDN 4 Sawah Lama Bandar Lampung TP 2019/2020

\section{Daftar Pustaka}

Hanafiah dan Suhana. 2009. Konsep Strategi Pembelajaran. Jakarta: PT. Refika Aditama.

Hidayati, dkk. 2008. Pengembangan Pendidikan Agama Islam SD. Jakarta. Dikti Depdiknas.

Kurnia Inggridwati, dkk. 2007. Perkembangan Belajar Peserta Didik. Jakarta: Dikti Depdiknas.

Nurmalawati. 2009. Upaya Meningkatkan Aktivitas dan Hasil Belajar Siswa dengan Menggunakan Metode Kerja Kelompok. Jakarta: Universitas Terbuka.

Sidiq, dkk. 2008. Pengembangan Bahan Pembelajaran SD . Jakarta: Dikti Depdiknas. 